\title{
DESCRIPTIONS OF TWO NEW SPECIES OF ENCYRTIDAE (HYMENOPTERA: CHALCIDOIDEA) FROM INDIA
}

\author{
M. Chand Basha ${ }^{1}$ and Mohammad Hayat ${ }^{2}$ \\ ${ }^{1}$ H. No. 16-5-206, 1/2 Balaji Nagar, Old Guntur, Guntur, Andhra Pradesh 522010, India. \\ ${ }^{2}$ (Corresponding author). Department of Zoology, Aligarh Muslim University, Aligarh, Uttar Pradesh 202002, India.
}

\begin{abstract}
Two new species of Encyrtidae, one each belonging to Caenohomalopoda and Mahencyrtus, are described from India.
\end{abstract}

Keywords

Indian Encyrtidae, descriptions, new species, Caenohomalopoda, Mahencyrtus

\section{Introduction}

The present paper is based on a small collection of encyrtids made by one of us (MCB) from Assam and Bihar. The species belong to two genera, viz. Caenohomalopoda Tachikawa and Mahencyrtus Masi.

The genus Caenohomalopoda contains four species: guamensis (Fullaway) from Guam Is., and Hawaii; Koreana Tachikawa et al. from Korea; nagaii (Tachikawa) from Indonesia; and shikokuensis (Tachikawa) from Japan, South Africa and U.S.A. C. koreana was recently recorded from India (Tamil Nadu) by Hayat et al. (2002).

The genus is characterised by the presence of a 4-segmented funicle; flattened and ventrally expanded antennal scape; fore wing with infuscate rays; a generally flattened bidy; presence of a pair of flattened scale-like setae at vertexo-occipital margin and at apex of scutellum. A key for seperation of related Habrolepidini genera was given by Tachikawa (1979). The species of this genus are parasitoids in Odonaspis species (Diaspididae) attacking bamboo.

The genus Mahencyrtus contains nine species known from the Australian, Oriental, Palaearctic, Nearctic and Neotropical regions. From India three species are known: $M$. assamensis Singh and Agarwal, $M$. indicus Singh and Agarwal and $M$. ranchiensis (Fatima \& Shafee) (see Hayat, 1999). The genus is well known, and is characterised by the presence of a triangularly expanded parastigma bearing a suberect seta, and longer propodeum with some sculpture (see Noyes \& Hayat, 1984 for characters of the genus).

\section{Caenohomalopoda longiclava sp. nov.}

\section{Material examined}

(Figs 1 - 4)

Holotype: Male (on card, with left wings and one antenna on slide), Patna, Bihar, India, 1.xi.1989, coll. M.C. Basha.

Paratypes: One male (on slide, one antenna missing), one female (on card, with right wings and antenna on same slide with holotype parts), Patna, Bihar, India, 1.xi.1989, coll. M.C. Basha.

\section{Distribution}

India: Patna in Bihar

\section{Etymology}

Latin: longus $=$ long, clava $=$ club. Refers to the long antennal clava in the male.

\section{Diagnostic features}

Male: Length, $0.97 \mathrm{~mm}$. Body dark brown to nearly black, metallic shiny, mainly bronzy-violet with bluish-green, especially on sides and apex (which are smooth) of scutellum; occiput, vertex from occipital margin to anterior ocellus, bronzy-violet; face bluishgreen, below toruli bronzy; scrobes bluish-green, bronzy above; malar space bronzy-violet. Scape white, with dorsal margin distally brown; pedicel largely dark brown; FI largely brown; distal third or so of clava dark brown; rest of antenna yellow. Wings hyaline; fore wing with a diffuse infuscation around distal veins. Legs dark brown except as follows: fore femur pale brown 


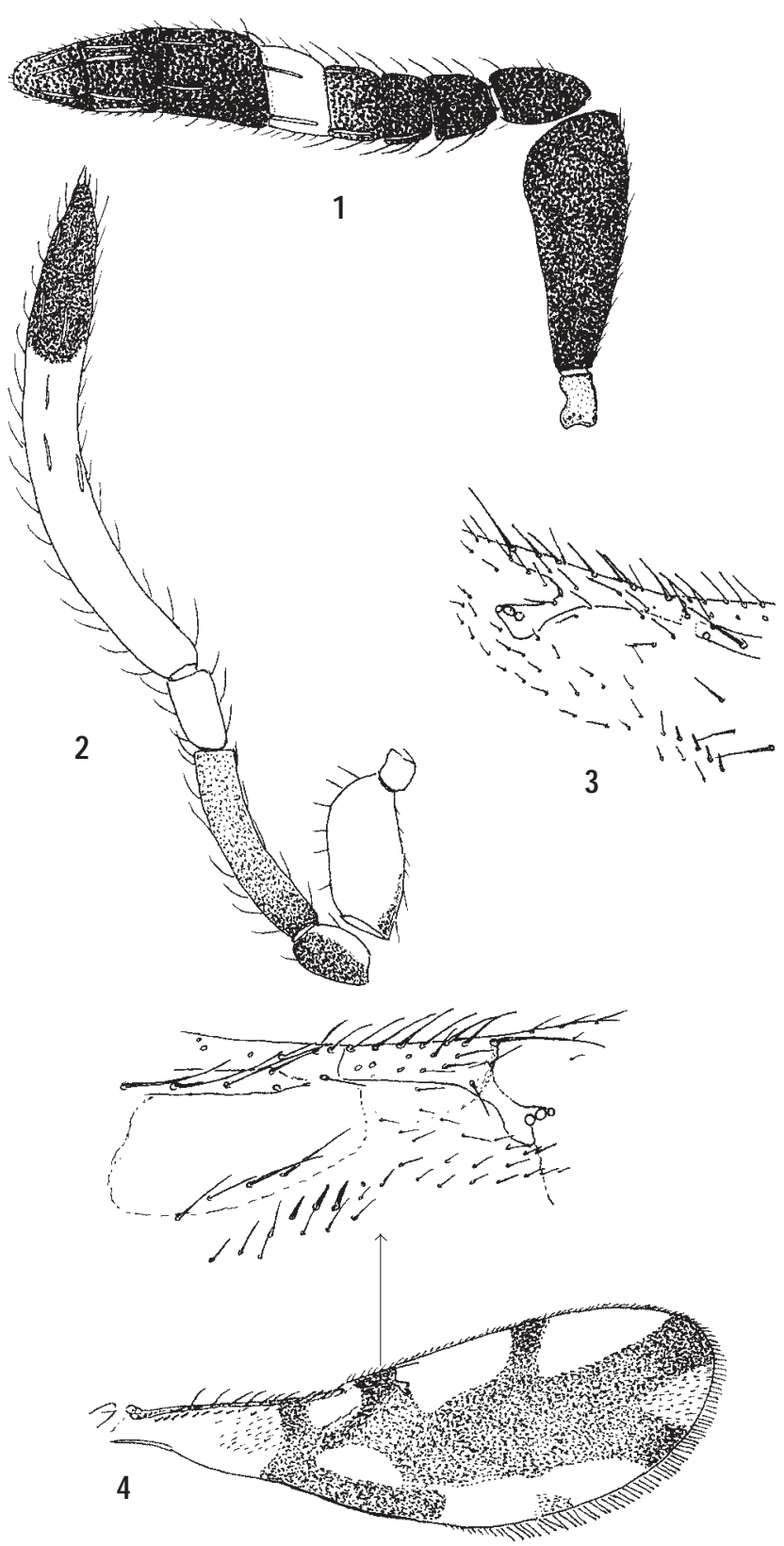

Figures 1-4. Caenohomalopoda longiclava sp. nov. 1 - Antenna of female; 2 - Antenna of male;

3 - Distal veins of fore wing of male; 4 - Fore wing of female (showing infuscated patterns, with distal veins enlarged)

with apex pale yellow; fore tibia brown, paler towards apex; mid tibia, except for a light infuscation at base, yellow; apex of hind tibia yellowish; tarsal segments 1-4 yellow, fifth segment brown.

Sculpture and setation as in female

Fronto-vertex about half of head width $(13: 25)$, and broader than length of scape (13:9); ocellar triangle with apical angle strongly obtuse; posterior ocelli slightly less than one diameter of an ocellus to eye margins, and about 1.5 diameter to occipital margin. Fore wing length : width, $106: 44$; hind wing length : width, $71: 17$. Pronotum, seen from above, narrowed anteriorly, slightly more than one-third of mesoscutum length $(2.5: 6.5)$. Antenna as in Fig. 2; distal veins of fore wing as in Fig. 3.

Female: Length 1.32mm. Body dark brown, metallic; fronto-vertex bluish-green, with anterior margin bronzy-violet; malar space and face bluish-green, with some bronzy-violet to purple tinge. pronotum and mesoscutum bluish-green, tegulae dark brown with violet tinge; medial half (triangularly reticulate part) of scutellum bronzy-violet, sides and apex smooth and purple; metanotum, propodeum and gaster largely violet; exserted part of ovipositor dark brown. Antenna dark brown except F4 which is white (Fig. 1). Fore wing with infuscated pattern as in Fig. 4; the hyaline areas, except the small triangular apical hyaline area which has dark setae, either without setae or with transparent setae infuscated areas with dark setae. Hind wing hyaline. Legs dark brown, slightly violet as mesopleura, except as follows: apex of fore tibia, distal two-thirds or so of mid tibia, and tarsal segments 1-4 of mid leg, and 1-3 of fore and hind legs, yellow.

Frontovertex with raised reticulate sculpture, cells small; pronotum and mesoscutum with transversely elongate to striate sculpture; scutellum punctate-reticulate in a median triangular area, with sides and apex broadly smooth. Frontovertex with white setae, including a transverse line of setae across anterior margin; the large scale-like setae (one pair at vertexo-occipital margin, and one subapical pair on scutellum) dark brown, thoracic dorsum with dark brown setae.

Structural details as in the figures and the relative measurements, but the following may be noted: Occipital margin with a median deeply concave emargination which is sharp; frontovertex flat with anterior margin straight and sharply separated from face which is obliquely bent downwards; ocellar triangle with apical angle obtuse; posterior ocelli about one ocellus diameter to eye margin, and about four ocellar diameters to occipital margin. Antenna as in Fig. 1; fore wing distal veins as in Fig. 4.

Relative measurements: Head dorsal width (medial length), 31.5 (11); fronto-vertex width, 12 (scape length, 12.5); pronotum length (width), 12 (26); mesoscutum length (width), 15 (27); scutellum length (width), 15 (17). Gaster length, 50, exserted ovipositor length, 7 .

\section{Remarks}

Although the female referred to this species appears to be very similar to females of $C$. koreana Tachikawa et al., this new species clearly differs in the males by the different dimensions of the antennal segments. The antenna in males of koreana has the 
clava clearly shorter than rest of the antennal segments combined, and at least distal half of clava dark brown (Tachikawa et al., 1981). In longiclava, the clava is as long as the rest of the antennal segments combined, and distal third of clava is dark brown. Because of the distinctive character of the male antenna, we have designated a male as the holotype.

\section{Mahencyrtus adelencyrtoides sp. nov.}

(Figs. 5 - 7)

\section{Material examined}

Holotype: Female (on slide under 4 coverslips, slide No.EH. 1003), Haflong, Assam, India, xi.1989, coll. M.C. Basha. Holotype retained in Hayat collection, Aligarh.

\section{Distribution}

India: Haflong in Assam

\section{Etymology}

Adelencyrtus + oides $=$ a contracton of Greek $-o+$ eidos $=$ likeness of form, and refers to the likeness of theis species to species of Adelencyrtus.

\section{Diagnostic features}

Female: Length, 1.85mm (holotype). Body dark brown, metallic; frontovertex dull bronzy-violet, with posterior half of vertex bluish-green, pronotum bronzy in middle, sides bluish-green; mesoscutum anteriorly and scutellum bluish-green, posterior two thirds or so of mesoscutum, axillae, scutellum anteriorly, bronzy-violet; metanotum, propodeum and gaster, except TI, dark brown with bronzy-violet; TI bluish-green. Antenna nearly unicolorous, testaceous yellow with upper margin of scape brownish, clava brownish. Wings hyaline; fore wing with a large infuscate patch on disc beyond venation leaving the margins hyaline. Legs pale yellowish, hind coxa basally brownish.

Frontovertex with raised reticulate sculpture and with fine setigerous punctures, mesoscutum with shallow reticulate sculpture; scutellum with raised reticulate sculpture deeper than that on mesoscutum and with sides and apex broadly smooth.

Head with frontovertex almost flat, and in profile, face abruptly bent downwards, and thus subtriangular (as in Adelencyrtus species); frontovertex one-quarter of head width (9:39) and $2.5 \mathrm{x}$ as long as broad (22:9), ocellar triangle with apical angle slightly acute; posterior ocelli nearly touching eye margins, and at least about 3 ocellar diameters to occipital margin; occipital margin rounded. Head, in front view, as in Fig. 6. Mandibles with two teeth and a small truncation. Antenna as in Fig. 5. Thoracic dorsum flat; pronotal collar biconvex, with a median notch. Gaster as long as head and thorax combined. Other details as in the relative measurements.

Relative measurements: (From slide): Head frontal width (height), 63 (51.5); frontovertex width, 16 (scape length, 25); mouth fossa width, 27.5; eye length, 38.5; malar space length, 20. Thorax length, 88; mesoscutum length (width), 44 (52); scutellum length (width), 30 (32); propodeum medial length, 6.5; distance between propodeal spiracles, 45 . Fore wing length (width), about 184 (65). Mid tibia length, 71; mid basitarsus length, 25; mid spur length, 24. Gaster length, 128; ovipositor length, 140; third

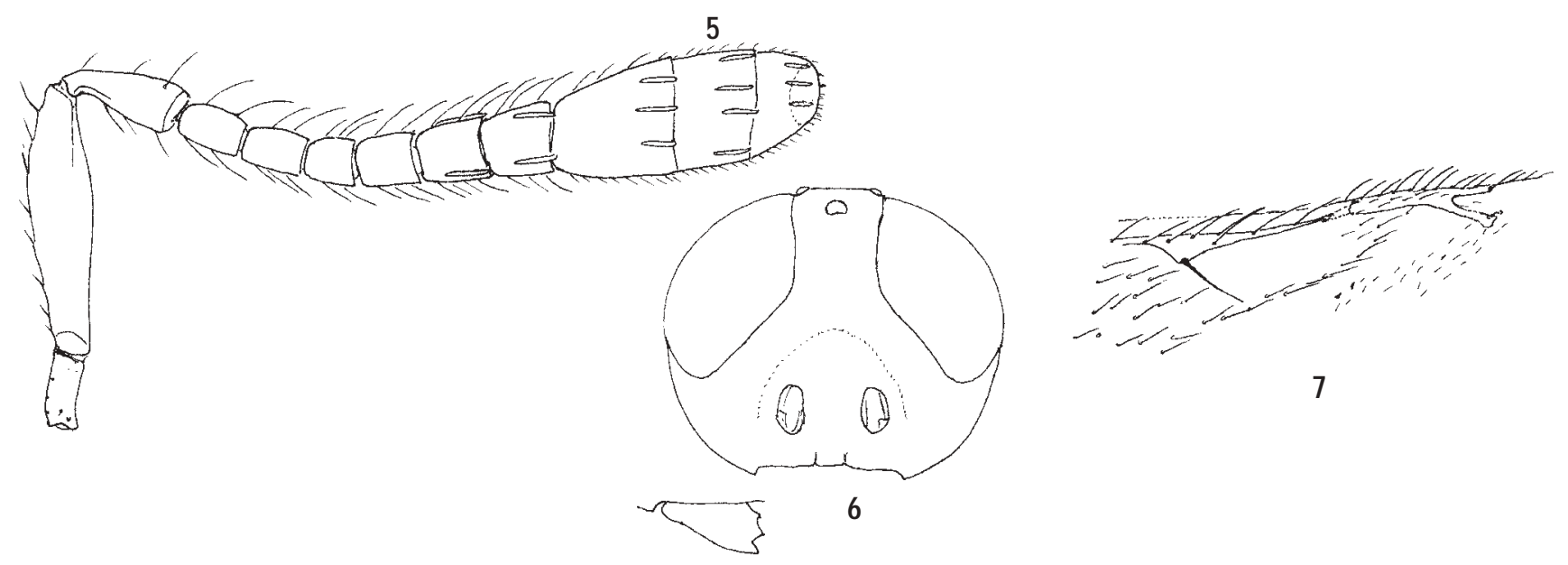

Figures. 5-7. Mahencyrtus adelencyrtoides sp. nov., (Female)

5 - Antenna; 6 - Head frontal, with mandible enlarged and shown separately; 7 - Fore wing venation 
valvula length, 39 .

Male: Unknown.

\section{Remarks}

This new species is placed in Mahencyrtus with some hesitation as the head is more or less similar to those of Adelencyrtus species in being subtriangular in profile, with the fronto-vertex almost flat. But in a majority of characters, including a distinctly triangularly expanded parastigma (Fig. 7), it is similar to other species of Mahencyrtus. However, the mandibles are with two teeth and a small truncation, not sharply three dentate as in Mahencyrtus, and the malar sulcus is absent. These characters suggest that $M$. adelencyrtoides sp. nov. may belong to a separate species-group in this genus. These characters also separate it from the other known species of Mahencyrtus (Hayat et al., 1975; Noyes \& Hayat, 1984; Singh \& Agarwal, 1993; Hayat, 1999).

\section{References}

Hayat, M. (1999). Taxonomic notes on Indian Encyrtidae (Hymenoptera: Chalcidoidea) V. Oriental Insects 33: 349-407.

Hayat, M., S.M. Alam and M.M. Agarwal (1975). Taxonomic survey of encyrtid parasites (Hymenoptera: Encyrtidae) in India. Aligarh Muslim University Publications (Zoological Series) on Indian Insect Types 9: $\mathrm{iii}+1-112$.

Hayat, M., S. Manickavasagam and S. Suresh (2002). Records of some Encyrtidae (Hymenoptera: Chalcidoidea) from Tamil Nadu, India. Zoos' Print Journal 17(4): 769.

Noyes, J.S. and M. Hayat (1984). A review of the genera of IndoPacific Encyrtidae (Hymenoptera: Chalcidoidea). Bulletin of the British Museum (Natural History) (Entomology) 48: 131-395.

Singh, S. and M.M. Agarwal (1993). Taxonomic studies on Indian encyrtid parasites (Hymenoptera: Encyrtidae) from northeastern region. Aligarh Muslim University Zoological Publications, Indian Insect Types 14: 180pp.

Tachikawa, T. (1979). A revision of the genus Pseudhomalopoda Girault with the description of a new genus (Hymenoptera: Chalcidoidea Encyrtidae). Transactions of the Shikoku Entomological Society 14: 163-170.

Tachikawa, T., W.H. Paik and J.C. Paik, (1981). A new species of the genus Caenohomalopoda Tachikawa (Hymenoptera: Encyrtidae) parasitic on Odonaspis secreta (Homoptera: Diaspididae) from Korea. Transactions of the Shikoku Entomological Society 15: 183-186. 